Research Article

\title{
The Road Less Traveled in Elementary Physical Education: Exploring Human Relationship Skills in Adventure-Based Learning
}

\author{
Paul T. Stuhr $\mathbb{D}^{1},{ }^{1}$ Tina De La Rosa, ${ }^{2}$ Amaury Samalot-Rivera $\mathbb{D}^{3},{ }^{3}$ and Sue Sutherland ${ }^{4}$ \\ ${ }^{1}$ Department of Kinesiology, California State University San Marcos, University Hall 318, 333 S. Twin Oaks Valley Rd., \\ San Marcos, CA 92096-0001, USA \\ ${ }^{2}$ McAuliffe Elementary School, Oceanside, CA, USA \\ ${ }^{3}$ The College at Brockport, State University of New York, 350 New Campus Drive, Brockport, NY 14420, USA \\ ${ }^{4}$ Department of Human Sciences, The Ohio State University, 305 West 17th Avenue, Columbus, OH 43210-1221, USA
}

Correspondence should be addressed to Paul T. Stuhr; pstuhr@csusm.edu

Received 25 September 2017; Accepted 22 January 2018; Published 26 February 2018

Academic Editor: Filipe M. Clemente

Copyright (c) 2018 Paul T. Stuhr et al. This is an open access article distributed under the Creative Commons Attribution License, which permits unrestricted use, distribution, and reproduction in any medium, provided the original work is properly cited.

\begin{abstract}
Teachers who are looking for ways to develop social and emotional learning with their students can use a curriculum model called Adventure-Based Learning (ABL). ABL consists of structured physical activities (cooperative in nature) with periods of reflection. The purpose of this study was to explore elementary physical education students' lived experience with intrapersonal and interpersonal relationship skills (IIRS) from an ABL unit of instruction. The aim of this study was to determine the credibility of an existing ABL student learning outcome model for use at the elementary school level in the United States. Findings indicated that the elementary students were able to connect, value, develop, and transfer the four IIRS over the course of the ABL unit. The findings provide plausible evidence that IIRS outcomes from the implementation of an ABL unit of instruction are possible to achieve at the elementary school level. Studies that further investigate student outcomes from participation in ABL at the elementary school level are recommended.
\end{abstract}

\section{Introduction}

Model-based practice (MBP) has been an innovative way to promote learning within the K-12 physical education (PE) landscape for decades [1]. These types of curricular models align with PE national standards within the United States (US) [2] and allow teachers to deliver content/activities in novel ways. Examples of MBP for PE include Sport Education [3], Cooperative Learning [4], Play Practice [5], Skill Theme Approach [6], Teaching Games for Understanding [7], Fitness for Life [8], and Adventure-Based Learning (ABL) [9] to name a few. There are essential elements for a curriculum to be included as an MBP. Each MBP has intended learning foci/goals, unique features/principles, and uses specific types of physical activity to help foster student achievement. There are also nuanced differences with each curricular model in regard to the implementation of PE for K-12 students. For example, Sport Education, Play Practice, and ABL have subtle differences when in comparison. Sport Education places emphasis on engaging students in an authentic sport experience while providing maximum opportunity to develop as a competent, literate, and enthusiastic sportsperson [3]. Sport Education uses six primary features to develop meaningful sport experiences for students: seasonal formats, affiliation, formal competition, records, culminating event, and festivity. Play Practice emphasizes acquisition of motor technique, skill, and game sense through progressive sequencing of physical activities [5]. The principles of shaping, focusing, and enhancing play provide the framework for which the games/activities are presented to students. ABL uses low initiative or cooperative activities coupled with periods of reflection [9]. ABL is a valid, standard-based curriculum 
model that can be used within PE to help promote intrapersonal and interpersonal relationship skills (IIRS) [2]. This qualitative investigation was conducted in order to explore student social and emotional learning (SEL) using the MBP of ABL at an elementary school located in the US. Specifically, the study sought to determine the credibility associated with an existing ABL outcome model [10].

Unlike outdoor or adventure education curriculum that takes place at the specialized adventure camps/settings, $\mathrm{ABL}$ is a "place-based approach" where the student-centered learning experiences occur at the school setting [11]. ABL "embodies a student-centered approach, encompassing a form of adventure, where the educative purpose of the experience is emphasized, and students reflect on their personal and social development through a debrief process" (p. 308) [12]. ABL emphasizes an experiential learning process that includes purposeful debriefing as the cornerstone feature to help students' process and transfer learning from the activities to their everyday lives. The content within ABL consists of highly structured and purposively sequenced physical (cooperative) activities coupled with periods of reflection called "debriefs" $[9,13]$. Teachers can use ABL to develop SEL, an ethic of care, and to start building a sense of community among teachers and students in physical education $[14,15]$. ABL in middle school physical education has been reported to help students develop IIRS, such as communication, cooperation, trust, and problem-solving social themes [10]. The design of ABL allows students to take part in cooperative activities that deemphasize a "win-at-all-cost" mentality that sometimes can be the principle mind-set of a sport culture PE environment. The nonzero-sum nature of ABL creates space for high amounts of opportunities for all students to participate at their own skill level. ABL as a curriculum model within elementary physical education holds tremendous promise as a valid and useful tool in helping physical educators develop IIRS associated with social and emotional learning.

1.1. Significance of the Study. There is limited empirical evidence illustrating the learning outcomes associated with a place-based ABL curriculum within K-12 educational settings $[12,14]$. In their review of outdoor and adventure education in PE, Sutherland and Legge [12] found very few place-based ABL studies conducted within the K-12 environment. Sutherland and Legge's review parallels Brown's [14] claim that there is still much work to be done when it comes to answering the question, "What do adventure education programs achieve in physical education" (p. 699). There are a few examples of empirical studies involving the implementation of ABL within the K-12 physical education setting [10, 16-19], yet ABL as a MBP has not been studied exhaustively. Relatively little is known in relation to student and teacher perceptions regarding their experience with $\mathrm{ABL}$ at the elementary school level. Furthermore, there are no known studies that have used the experiential learning process to implement ABL at the elementary school level. With the aforementioned in mind, the purpose of this qualitative case study was to explore the development of social and emotional outcomes (i.e., IIRS) produced by an
ABL unit within an elementary school context and determine the credibility of an existing ABL student learning outcome model that had been previously found credible at the middle school level.

\section{Conceptual Framework}

Experiential learning theory (ELT) was used to frame this study and as a means to keep central to the investigation the importance of conducting reflective debrief sessions within ABL in order to promote social and emotional outcomes. This study used two similar yet different ELT models to encapsulate the lens through which the study was conducted, and data were analyzed, organized, and discussed. Using the Experiential Learning Cycle [20] and the Sunday Afternoon Drive Debrief Model (SADDM) [21, 22] allowed the researchers to view the learning process from a social constructivist lens in order to interpret the situated knowledge construction of the participants involved in the study. The epistemological and the pedagogical ramifications from using these models helped guide the delivery of the ABL content, as well as analyze and discuss the data. These ELT models will be discussed further to provide the centrality that they played in the learning process specific to this study.

2.1. Experiential Learning Theory. Broadly defined, ELT is knowledge construction through the act of doing with reflection [23, 24]. Dewey's [23] hands-on educational approach emphasized a learning environment in which students are free to interact with others (i.e., teachers and other students), where the content was relevant and intrinsically motivating to the learners, and from which reflection could occur on an ongoing basis. ELT can be viewed as a sequential process that includes a variety of components or steps that promote change and transferability of intended skills presented to the learner [15]. ABL research and to a greater extent the field of outdoor adventure education (OAE) have used ELT as the primary epistemological lens through which to frame the learning process [12]. Priest and Gass [24] noted that, out of all the ELT models [25-27], Kolb's [20] experiential learning cycle (ELC) is the most widely known and used within OAE. It should be noted that although quite popular and well known within the experiential education literature, Kolb's ELC does have its critics who have postulated opposing thoughts in regard to the viability of the assertions within the theory itself $[28,29]$.

2.1.1. The Experiential Learning Cycle (ELC). Conceptualized by Kolb [20] and later repositioned by Kolb and Kolb [30], the ELC is based upon the work of some of the prominent historical EL theorists to date (e.g., John Dewey, Kurt Lewin, Jean Piaget, William James, Carl Jung, and Paulo Freire, among others). Kolb and Kolb outlined six leading theoretical assertions embedded within the ELC based upon the work of these scholars (Table 1). 
TABle 1: Theoretical assertions within the experiential learning cycle (Kolb and Kolb [30]).

Leading ELC theoretical assertions

(1) Learning is a process of experience in which the focus of teaching should lie with creating space that fully engages students in the instruction, with formative feedback to help shape intended educational goals.

(2) Learning is a continuous cycle predicated on past experience and history of the student. Thus, learning is more of a cyclical relearning process, providing students with opportunities to examine previously learned knowledge with newly proposed ideas.

(3) Learning itself embodies conflict, in which the student must consciously reflect in and on the action of experience. This adaptive process of going from experience to reflection and back facilitates the enduring understanding of knowledge (i.e., learning).

(4) Learning is holistic. Knowledge construction requires the totality of one's being (i.e., learning involves thoughts, emotions, subjective perception, and overt behavior).

(5) The environment plays a key role in the learner's ability to assimilate new ideas or knowledge.

(6) The ELC is built upon constructivist theory where knowledge is active and socially created (i.e., hands-on and doing) rather than passively transmitted (i.e., watching, listening, or reading) to the individual.

Based upon these six assertions, ELC is a learning model comprising four stages (i.e., experience, reflection, conceptualization, and application). The learner progresses through each stage with the goal being construction of new experiences and/or knowledge. Stage one (experience) is the individual or group performing some type of instructional task or experience. Stage two (reflection) is the individual or group becoming involved in processing the experience, reviewing what has taken place during the task and even questioning what took place. Stage three (conceptualization) is the process of identifying what happened in the experience (i.e., concept or idea formation), analyzing it, and then making connections or new understanding. Stage four (application) provides space for discussing how one could test or use the newly acquired knowledge within the personal life of the individual or group (i.e., apply the learning from this experience to other settings). This ELT is a cyclical model that postulates learning as a continuous process in that what has been acquired from one experience goes with the learner into the next situation, task, or experience.

2.1.2. The Sunday Afternoon Drive Debrief Model (SADDM). A widely shared premise with ELT (and ABL for that matter) is that reflection is one, if not the most, essential component at the heart of knowledge construction [31]. There are a variety of approaches that have been used within OAE and ABL to promote the reflective process within ELT, such as the Funnelling Approach [32], the Outward Bound Plus model [33], and the SADDM [21, 22]. This study used the SADDM. The SADDM is a modified version of Kolb's ELC that includes philosophical and pragmatic pedagogical tools for which the ABL instructor can use when attempting to carry out student-centered reflection sessions. The model has been reported to be a valid and credible framework for conducting reflection (i.e., ABL debrief sessions) that provides K-12 students with an opportunity to conceptualize transfer of IIRS to settings outside the school environment $[10,21,22]$. The model is based on a "car and driver" metaphor in which the group "drives" the conversation following a "route" toward a facilitated "destination." The use of the "driving a car" metaphor provides a means through which to organize the debrief process that occurs in ABL.

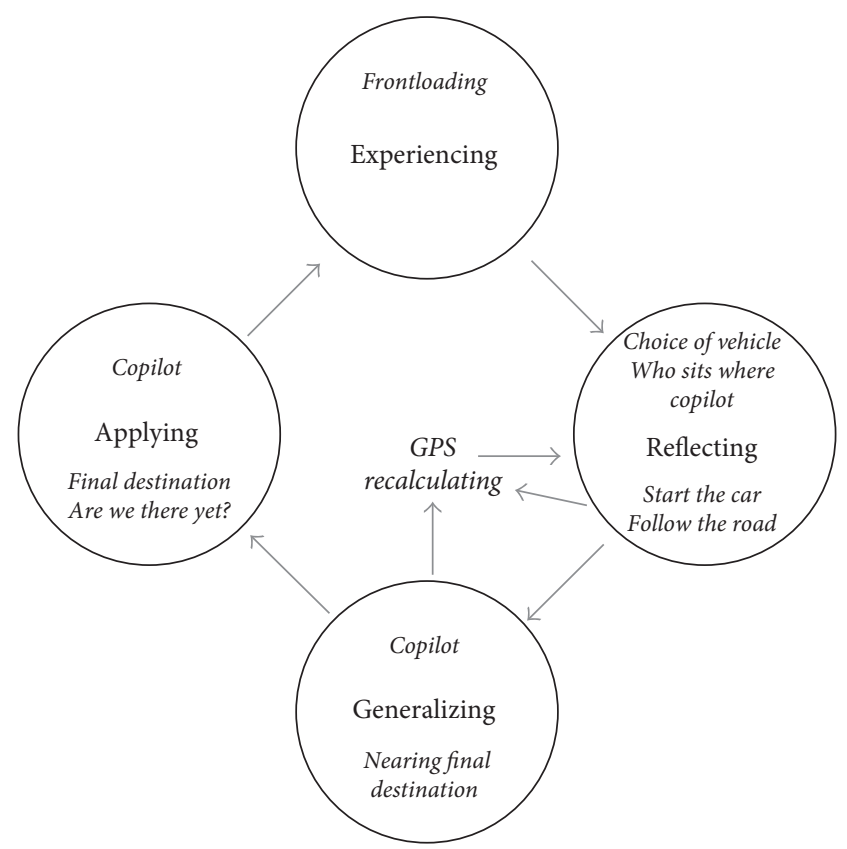

Figure 1: Sunday Afternoon Drive Debrief Model (Sutherland et al. [22]; Stuhr et al. [15]).

A roadmap (i.e., lesson plan) exists for the start of the drive (i.e., facilitator has questions and simple activities to help promote discussion), however, the facilitator follows the various paths and roads (i.e., ABL group conversations) as they negotiate the journey (i.e., the reflective period) towards a final destination (i.e., an end result or outcome that can be used by the participants). (p. 24 [21])

There are nine features embedded within the SADDM: frontloading the experience, choice of vehicle, who sits where, copilot, start the car, follow the road, GPS recalculating, nearing the final destination, and final destination (Figure 1).

The model starts with frontloading the experience (a.k.a. the brief). This typically requires the ABL instructor to use some type of "hook" or anticipatory set to spark the learner's interest and help them to start thinking about what might the experience entail. Instructors can use quotes, short stories, pictures, or other modes of pedagogy to frame a particular IIRS that they would like the learner to explore 
further once in the experience/ABL activity and then in the debrief. Once the activity is concluded, the instructor and all students will create a "talking circle" (i.e., tightly formed, seated, and closed circle on the ground). This circle is called who sits where in the car? and represents the first part of the reflective stage in the model. "A circle formation is a nonverbal signal to the students that they are in control of the discussion" (p. 32) [21]. The copilot feature of the model highlights the instructor and students as co-participants in the conversation/debrief. The copilot's role is not to dictate or provide direct instruction regarding the conversation, rather their role is to get students talking, provide guidance (if necessary), and then fade away once the students understand that they are in control of the debrief topic and flow of the conversation. The start the car strategy within the model depicts a novel way to get the conversation going. Start the car strategies provide the learner with an opportunity to reflect on "what happened" during the ABL experience/activity. There are many different strategies an instructor can choose from to start the car (e.g., picture postcards, completing a written prompt, with a partner create a headline of the experience, and choose a quote among several provided that represents the experience). The size of the conversation is represented with the choice of vehicle feature. Before students start to talk, the instructor needs to make a decision on how large the reflective group will be (e.g., pair, trio, small group, whole class, and individual). Smaller groups produce more "student voice" (i.e., opportunity to speak) and typically reduce the pressure or even anxiety for children to converse (i.e., smaller groups create higher level of comfort speaking). Follow the road is arguably one of the more difficult features for teachers to use within the model. This strategy is about how the instructor goes about guiding the students through the conversation. Here, the instructor listens carefully to students' comments and identifies the most powerful or compelling comments that provide potential for student SEL to occur. There are several strategies that instructors can use to follow the road of the conversation (e.g., paraphrasing participants' comments, taking notes on key words or phrases, asking probing questions to gain deeper insight, providing positive acknowledgement when a student makes a relevant, powerful, or exemplar comment, and asking students to further elaborate on key statements to get them to think and go deeper into what they actually mean). The primary reason to use the GPS recalculating feature in the model is to help redirect the conversation. When the conversation "gets off track" or students stop talking, the instructor can use preplanned questions to help guide students back to an appropriate conversation. The nearing the final destination feature provides the instructor an opportunity to help students gain a deeper understanding of "what happened" in the experience. Here, the instructor narrows the conversation down, highlights any "take home message," guides the students to think about their experience conceptually in terms of the most important IIRS that was discussed, and asks to students to think about "why" the IIRS is important to them. The last feature of the model is the final destination. This feature represents the potential for students to transfer the discussed IIRS to areas outside the classroom. In this part of the debrief, the instructor helps students think about the IIRS in ways related to real-world or authentic situations. The nine features of the SADDM extend and shape Kolb's ELC for teachers who use ABL. The effectiveness of the SADDM has been mixed with further exploration needed within the K-12 context $[10,19,21,22,34]$.

\section{Methods}

The purpose of this study was to ascertain two primary thoughts of inquiry: how and in what way was social and emotional learning experienced in $\mathrm{ABL}$; and were the participants able to connect with, value, develop, and transfer the four IIRS embedded with the ABL unit, thus in essence, helping to determine the credibility of an existing learning outcome model. A qualitative case study was used in the design and delivery of this exploration [35]. The use of instrumental case study design [36] was appropriate considering we wanted to identify, understand, and refine how the participants (teachers and students) experienced and navigated through the use of the two existing ABL models: SADDM and Student Learning Outcome Model. Using an instrumental case study design allowed the focus to be on capturing data that best represented the use and outcome of these two models, and thus help determine what, if any, refinement or reconceptualization was needed with these ABL tools.

3.1. Settings and Participants. This case study took place in a fifth-grade elementary PE class at a school located in the southwest portion of the US. The location of the school could be considered low-middle class with a median household income in the city of $\sim \$ 58,000$ (US dollars). According to the district's demographics, the diversity of the total enrolled student body for this school consisted of eight different ethnicities (i.e., African American 3.9\%, American Indian 0.4\%, Asian 3.3\%, Filipino 1.8\%, Hispanic 46.8\%, Pacific Islander $0.9 \%$, White $40.2 \%$, and two or more races $2.2 \%$ ). According to the school's accountability report card, $46.3 \%$ of the students were classified as socioeconomically "disadvantaged" and qualified for either free or reduced lunch based upon family income. $24.8 \%$ of the students were classified as English Learners. A total of 32 students (18 female and 14 male) were in the class that the study took place. 28 students (and their parent's/guardian's) provided consent to participate in the study. The ages of the students ranged between 10 and 11 years old. None of the students in this class had ever experienced an ABL unit at school. Two teachers participated in the study (an elementary classroom teacher and the PE specialist). Both teachers had over 25 years of experience in teaching at the elementary level. The classroom teacher was a former elementary school principal, and the PE specialist was a National Board Certified Teacher. Neither teacher had taught an ABL unit prior to this research investigation, yet both teachers commented that they were "thrilled" and "excited" about the prospect of learning about and teaching ABL to their students. Not having used, nor having knowledge of ABL in the United States is quite common because most PE programs use sport 
or fitness units commonly referred to as a multiactivity model [3]. As such, the students in this study had experience participating in skill-based and fitness activities for PE.

\subsection{ABL Programming}

3.2.1. Prestudy Teacher Training. The implementation of the ABL unit was closely supervised by the PI with additional training and support on the nuances of each activity provided to the PE specialist. The prestudy training consisted of a 5-hour ABL workshop, and four, 1-hour face-toface meetings prior to the start of the unit. At the workshop, the MBP of ABL was introduced, and the teacher was given opportunity to participate in 10 activities (which included discussion/participation in the brief and debrief portion of $A B L)$. At the face-to-face meetings, each ABL activity and IIRS planned for the study was introduced and discussed with the PE specialist. To help with the integrity of the ABL unit, the principal investigator (PI) (who had more than 15 years experience teaching/facilitating adventure education) had carefully planned all lessons. The written lessons, provided to the PE specialist listed a sample brief, the ABL activities, and sample debrief questions. Once the prestudy training concluded, it was the responsibility of the PE specialist to study the lesson plans and make any additional modifications/preparations for the delivery of the unit.

3.2.2. ABL Activities. A total of $17 \mathrm{ABL}$ activities were planned and taught by the PE specialist. The activities followed a sequential order and were aligned to one of the four IIRS that were introduced and discussed throughout the ABL unit. The activities were aligned to the following IIRS theme and taught in this order: Commitment: Hustle Bustle; Categories; Group Bingo; and Help Tag. Helping others: Dead Ant Tag; Popcorn; Group Juggle; and Human Knot with Buddy Rope. Responsibility: Human Camera; Speed Rabbit; King, Queen, Frog; and Balloon Trolley. Leadership: Giants, Wizards, and Elves; Toss Five; Moonball; Negotiation Square; and Key Punch. The lesson plans and activities were modified from two initial sources: journey toward the caring classroom: using adventure to create community in the classroom [37] and adventure curriculum for PE middle school [38]. These ABL sources were chosen as the curricular unit because they have been used in the past to help promote IIRS with students [10, 12, 21, 22].

3.2.3. The IIRS. The four IIRS were introduced in the ABL briefs, immediately practiced within the ABL activities, and then reflected on during the debriefs. Each IIRS was carefully aligned with the ABL activities. For example, the IIRS of helping others complimented and was aligned with the activities of dead ant tag, popcorn, group juggle, and human knot with buddy ropes. The selected activities and IIRS aligned with state [39] and national content standards from the US [2]. The intact ABL unit was also approved by the site principal and school district.
3.2.4. Structure of the ABL Facilitation. Elementary PE at this school was to be conducted for a total of 200-minutes every 10 days, per California state requirements. Typically, the PE specialist taught this class for 30 minutes each week, while the classroom teacher was expected to conduct PE with these students for the remainder of the required minutes. During the study, the PE specialist was able to see the students two times each week (30 minutes per session). The PE specialists taught 10, 30-minute lessons, and the classroom teacher conducted 10,15-minute debrief sessions (two per week). Thus, the unit occurred over a 5-week time span. Once the unit was complete, the PE specialist had conducted 10 briefs, 17 activities, and 10 debriefs. And the classroom teacher had facilitated an additional 10 debrief sessions with the students once they had returned from PE. Both teachers communicated daily, with each other, to verify that they were both covering the same IIRS for the ABL lesson. Both the PE specialist and classroom teacher used the SADDM when conducting each reflective debrief sessions. For each $\mathrm{ABL}$ lesson, there were 20 minutes allotted for the brief and activity, and 10 minutes allotted for the debriefalthough these times varied slightly and adjusted by the PE specialist depending on the lesson flow. All ABL activities were videotaped to determine the fidelity of implementation, based upon the prestudy workshop and face-to-face training that occurred with the PE specialist.

3.3. Data Collection. An ABL student learning outcome model [10] guided the naturalistic data collection approach. Data from 28 5th grade students were collected through interviews, written journals, and a modified photovoice [40] assessment. As a means to keep track of where each datum came from (i.e., source location) the following provenances were used: individual interview (II), small group interview (SI), written journal (WJ), and photovoice journal (PJ). For example, (II, 5) would represent an individual interview that occurred during week 5 of the study. Whereas (SI, AU, G2) would represent a small group interview that occurred after the unit (AU) was completed with group number 2.

3.3.1. Interviews. During weeks 4 and 5 and upon completion of the ABL unit or after unit (i.e., AU), all students were interviewed in regard to their understanding and use of the four IIRS that were taught, practiced, and reflected upon. Students participated in one individual and one small group (3-4 students) interview. The interviews were face-to-face, semi structured, and allowed for predetermined questions to be asked, with opportunities to explore the student responses further (if needed). The 10- to 30-minute interviews included questions that focused on allowing the students' share their lived experience of the ABL unit, specifically the four IIRS.

3.3.2. Written Journal. The classroom teacher was asked to have the students write for 30 minutes, four times throughout the duration of the unit. The totality of these writing sessions became the writing journals that were used for analysis. The teacher provided the students with the 
specific IIRS topic (i.e., commitment, helping others, leadership, or responsibility) and three prompts: Describe what the IIRS means to you, provide an explanation of how the IIRS was used or related to a particular ABL lesson, and what you have recognized about how the IIRS is present or connected to your life. In addition to providing the prompts, the classroom teacher took 5-10 minutes to discuss the prompts and answer any student questions.

3.3.3. Photovoice: Drawing Journal. The photovoice method is an innovative approach that provides the participant an opportunity to "tell their story" in regard to a specific topic, theme, or phenomenon through pictures and written narrative [40]. Each student completed a modified photovoice journal that was related to the IIRS covered in the unit. Since the majority of students did not have access to a camera, drawings became a viable way to collect data and still use the photovoice approach. The classroom teacher provided time for students to draw a picture that represented the use of one of the relationship skills from the ABL unit. Then, the students were asked to write a narrative describing their picture in relation to how the IIRS is/was practiced in or outside of school. The classroom teacher provided three prompts for the photovoice journal: Name one IIRS and explain what it means to you. Why is your chosen IIRS important? And how do you use this IIRS in or outside of school? Using photovoice method provided another source of the students' lived experience of the IIRS that were taught, practiced, and reflected upon within the ABL unit.

3.4. Trustworthiness. This study used five strategies to establish trustworthiness. These strategies are commonly used in qualitative inquiry to produce valid and reliable findings [35]. Trustworthiness as defined by Guba and Lincoln [41] was established through triangulation of data sources, prolonged engagement, member checking, peer debriefing, and thick description of the data. Four sources of data (individual and small group interviews, written journals, and photovoice method) were collected and triangulated through the data analysis process. Analyzing the coded data to determine which emerging themes/findings appeared across several sources and participants ensured that triangulation was performed. The researchers spent a total of 22 weeks engaged with the teachers and students, from the initial prestudy training through the final follow-up interviews with the teachers and students. Three small group follow-up interviews occurred 5 weeks after the ABL unit. These interviews were used specifically to help with the member checking process. Students were asked specific questions pertaining to the developing themes that came from the transcribed data corpus. Written journals were used as another way to conduct the member checking process (i.e., the written journals helped with the credibility of the other data sources). To determine a degree of confidence in regard to the data corpus and the developing themes (i.e., confirmability with the findings), the PI conducted three peer debrief sessions with a higher education colleague who had a background in outdoor adventure education. This process required sending an abridged version of some of data transcripts to determine alignment with the developing themes. The setting, participants, and findings were written with rich and thick description to help the reader contextualize the study and to determine the extent to which there is consistency in the findings. Rich description promotes the possibility that such findings could transfer to another setting.

3.5. Data Analysis. The data analysis process used a quasiinductive approach that consisted of open and selective coding [42]. The selective coding process coincided with a modified, deductive approach [43] that allowed for preexisting categories (i.e., a priori assumption about an existing theory) to help guide the data analysis process. The coding was completed in a two-step process. Data was transcribed, and then the organizing of a codebook through the labeling of pieces of data occurred (i.e., open coding). The codebook took on various iterations, as the transcripts were read and reread. As the codebook matured, initial themes were interpreted from the data corpus (i.e., assertions were constructed). The second step required using existing themes from a previous study [10] and rereading parts of the data transcription in an attempt to confirm, reject, and modify the priori assertions (i.e., coding that followed a deductive approach). Concurrently, during this step, transcriptions were sent, with assertions/themes to another higher education colleague for the peer debrief (i.e., to determine whether the assertions were on the right track in terms of identifying and interpreting the data corpus).

In the case of the modified deductive approach (i.e., use of preexisting categories), an ABL Student Outcome Model [10] was used to help guide this selective coding (Figure 2).

This model represented a theoretical lens through which to confirm or reject a priori theory. The model is a theoretical representation of the four learning stages that students can reach/acquire through their participation in ABL. Stage 1 (Connecting) is based upon whether or not the participant has an affinity toward the ABL curriculum (i.e., did students' perceive the ABL experience as enjoyable?). Stage 2 (Valuing) looks at whether the participant sees the IIRS as important (i.e., did students' perceive the four IIRS as useful?). Stage 3 (Developing) is about whether or not the participants believe they have been given opportunity to expand on or mature their understanding in relation to the IIRS (i.e., did students' honestly see themselves being able to work toward personal growth as it related to the four IIRS?). Stage 4 (Transferring) refers to the participants' ability to make the connection of how they currently (or could in the future) use the IIRS within their life (i.e., did students' comprehend how IIRS could be advantageous outside of $\mathrm{PE}$ ?). The outcome model served as a theoretical frame during the data analysis.

\section{Findings}

This qualitative case study explored the lived experience of 28 elementary school students during their journey with an ABL curriculum. The study looked to explore how the elementary students represented four preselected IIRS (i.e., commitment, helping others, leadership, and responsibility) 


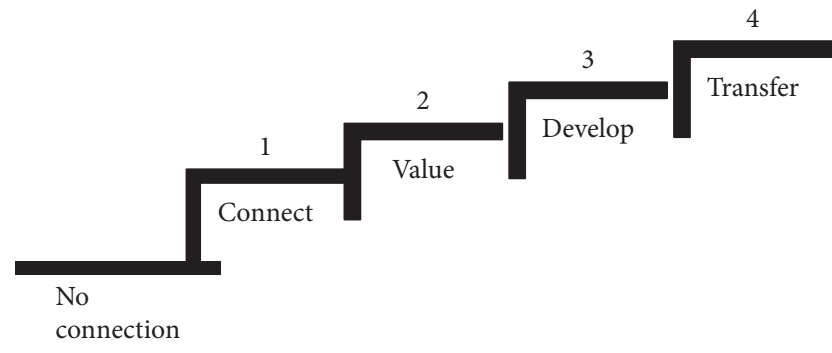

Figure 2: ABL Student Outcome Model (Stuhr et al. [15]).

that were taught, practiced, and assessed within the unit. By examining the students' perception of these IIRS, the hope was to determine the fidelity of an existing ABL outcome model [10]. The researchers assert that this model can be a credible and theoretical way to view ABL outcomes with younger, elementary students-findings that are yet to be fully explored with this age group with $\mathrm{ABL}$ in $\mathrm{PE}$.

The data did in fact represent the four stages from the existing ABL outcome model. These stages included the following: connecting to the activities in the ABL unit, valuing the four IIRS that were embedded in the curriculum, perceiving opportunity in developing the IIRS, and expressing thoughts, ideas, and examples of how the students could or were transferring the IIRS outside the scope of the ABL unit. The four IIRS (covered in the ABL unit) surfaced from the data corpus as legitimate outcomes through the discovery of the following four themes: affinity toward $\mathrm{ABL}$, meaning and importance of the IIRS, identifying personal development with the IIRS, and benefit of IIRS outside of PE.

4.1. Affinity toward $A B L$. Students represented stage 1 (Connecting) as showing affinity toward the activities, as a result of their participation in ABL. The emerging data led to the discovery of three features in regard to having an affinity toward ABL: the students in this study (a) were eager to participate, showed an affiliation toward the activities, and had fun, (b) were physically engaged, and (c) understood that there was a purpose behind doing ABL. The participants in this study spoke highly about ABL, "Yes. These games are really fun" (SI, 4, G2). Other similar comments from students included, "These are really, really fun activities" (SI, 5, G4)! "I would like to do more" (SI, 4, G5). "When will we get to do [ABL] again" (SI, 5, G2). As seen in previous works, using adventure-type curriculum can promote the level of enjoyment students receive in PE compared to a "traditional" class $[44,45]$. The students indicted that ABL was not only enjoyable but kept them physically active as well, "Yes, we have fun and we get a work out" (SI, 4, G1). Similarly, one student indicated, " $[\mathrm{ABL}]$ is fun, but we also get exercise and sweat" (II, 5). While one student commented, "[ABL] makes me feel like I have butterflies in my stomach, in a good way. I get to have fun, exercise, and be with friends. This makes me happy and have butterflies ..." (II, 5). There was also the realization from the students that $\mathrm{ABL}$ was more than merely "fun and games," that learning about social and emotional skills was part of this educational process, "Yeah, I like $[\mathrm{ABL}]$ because they introduce us to stuff about life. They are pretty fun for kids but also we learn" (SI, 4, G3). Another student commented, "[ABL] is fun but you are able to learn...I think it's fun and beneficial" (II, 4). Probably, the most creative stage 1 comment was when one student related ABL to ice cream, "To me it's like eating ice cream. It's fun and delicious! But if you eat ice cream too fast you get a brain freeze. You can have fun in PE, it's ok, but it's also important to take your time and learn something. .. if you go too fast doing this $[\mathrm{ABL}]$ then you don't learn" (SI, 2, G1). As with previous findings at the middle school level [10], participants in this study found the ABL activities to be enjoyable. The findings from the data corpus represent an established connection between the students and their lived experience with the $\mathrm{ABL}$ unit (i.e., illustrating stage 1 credibility at the elementary level).

4.2. Meaning and Importance of the IIRS. The students were able to articulate the meaning of the four IIRS (i.e., commitment, helping others, leadership, and responsibility) and justify the importance of using the IIRS covered in the ABL unit. Having an understanding of the IIRS is one of the first steps toward demonstrating the value it potentially can have for an individual (i.e., educators should not expect students to value what they don't understand). In regard to the IIRS of commitment, one student wrote the following:

Commitment is to do what you are asked to do. Commitment is to give best effort. When someone asks you to make a promise, you're committed not to break it. If you break that promise you lose trust from that person. At school, you're committed to do your work. At home, you're committed to chores. For sports, you're committed to do it and try your hardest. You should always be committed to do what you're supposed to do. (WJ)

This student recognized commitment as a "best effort," "a promise," and as a way to form trust with others. Another student indicated that commitment started with believing in yourself:

Commitment is to believe with all your heart you can do something. Another meaning for commitment is to do your best in school. Try to challenge yourself by committing to that goal. When you commit it helps you become a better student or grownup. In school or in any place you should challenge yourself to be committed and do the right thing. (WJ)

It was interesting that this student understood the value that commitment could have for their future self. As it related to the IIRS of helping others, one student wrote, "Helping others is about doing something nice for someone without them asking. It's about lending a hand to someone in need" (SI, 5, G1). This individual positioned helping as something that should occur regardless of whether someone asks for it. While a different student related helping others as, "being an excellent role model and showing others what should be done" (WJ). The participants also had a solid grasp 
on what leadership was, "Leadership is about taking a stand. If somebody is being mean to you and people think it's wrong then they all stand up against that person and tell them that's wrong" (SI, 4, G3). Here, the student uses the example of standing up to a bully to represent leadership. Whereas another student believed leadership to represent doing "good" without any desire to receive something in return (i.e., being altruistic or selfless), "The lesson I am learning about leadership is that doing a good deed doesn't need a reward. Doing a good deed without a reward means you care about that person not the reward, that's real leadership" (WJ). Responsibility was defined as, "... .being willing to own up for your actions. If you ... don't follow the directions then you won't be taking responsibility for your actions" (SI, 4, G1). One student acknowledged that responsibility was, ". . . doing what is asked by the teacher and making sure you do it" (WJ).

The students also acknowledged the importance in learning about and practicing the IIRS (i.e., they found the IIRS to be a useful part of their education). The students understood that ABL had real merit that the IIRS being practiced were important and could benefit them in their lives, "[The IIRS] will help you to become a better person. You get to learn these skills in PE because later people are going to need help and you'll be better to help them" (SI, AU, G1). Another student made the same link between learning the IIRS now in order to apply this knowledge down the road, "I think [the IIRS] are important so that we know how to work together and how to do more things in the future. People will actually need you sometimes and you need them. So yes they are important to learn now" (SI, 4, G2). One student wrote specifically about the importance of helping others as part of a desired character trait that helps to define who they are (or wish to be) as a person:

I am glad we are learning about helping others. I think it is important to behave this way because you're going to have to learn to help others, know that it is good to help others, and being capable of helping others is a wonderful characteristic to have. (PJ)

Students also commented on how the IIRS were "valuable" to learn for purposes of teamwork:

"[The IIRS] are valuable because when we did the toss 5 we learned not to yell at them when they drop the bean bag and instead say, "it's ok." We learned how to work together and we did [finish the goal of the activity]." (SI, 5, G5)

This particular student understood the importance of the IIRS in regard to the outcomes of the ABL activities. The students in this study recognized that the process, and how they interacted with one another, was just as important as completing the activity.

The data from this subtheme illustrated that the students were able to capture and articulate the meaning of the four IIRS. The students were also able to justify the importance of learning about the IIRS during the ABL unit. There is a place for the use of social skills and other types of social and emotional learning (SEL) within PE-the field of $\mathrm{PE}$

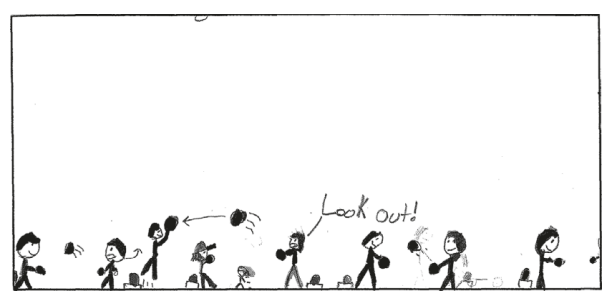

FIgUre 3: Photo journal drawing representing stage 3: developing commitment.

acknowledges their importance as one of several intended learning outcomes for children [2]. The findings brought to the surface how the IIRS were defined and just how important they were to the students. The findings from stage 1 and stage 2 assert that the students not only enjoyed ABL (stage 1) but also found value (i.e., personal meaning) in learning about IIRS (i.e., illustrating stage 2 credibility at the elementary level).

4.3. Identifying Personal Development with the IIRS. Stage 3 represents the broadening of understanding toward the development of the IIRS. Students at this stage consciously acknowledge being able to work on self-attainment and improvement of the IIRS within ABL (i.e., students identify that learning of the IIRS is emerging). At this stage, the goal is to have students realize that PE is more than "fun and games," that when it comes to ABL there are intended SEL outcomes in place for them to be working on. Within the data corpus each of the four IIRS (i.e., commitment, helping others, leadership, and responsibility) emerged, as students were consciously identifying personal development (i.e., stage 3 ) with the IIRS.

4.3.1. Developing Commitment. Two students spoke about how being a good listener was a way to model commitment within the group, "I think I was showing commitment today by listening to my group. Yes, he was listening, I saw him" (SI, 4, G2). As seen in Figure 3, one student was able to capture commitment through his photo journal drawing:

We were doing [group juggle], and my throw overshot. It wouldn't have been a problem if it hadn't been heading straight for another person. So I shouted "look out" and the person caught it. I was committed not to let another person get hit with the ball. (PJ)

This student believed his actions kept another student from being hit by the ball; showing his intent to keep others safe in lieu of a possible dangerous situation was a sign of his commitment to his classmate.

4.3.2. Developing a Helpful Presence (i.e., Helping Others). As represented in Figure 4, the acknowledgement of using the IIRS of helping others emerged from the data quite often:

During PE I was helping others for my team in [balloon trolley]. It was tricky because the balloons kept popping and falling because everyone went too fast. I soon grew enough 


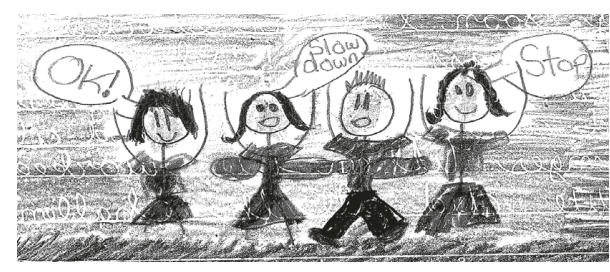

FIgURE 4: Photo journal drawing representing stage 3: developing a helpful presence.

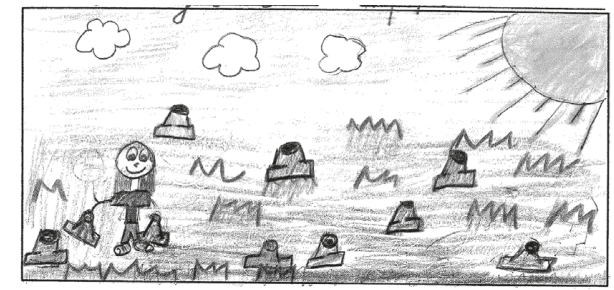

FIGURE 5: Photo journal drawing representing stage 3: developing leadership.

courage and shouted, "Slow down, we're going too fast!" We all slowed down and kept going. Soon the balloons started to fall again to the ground. "Pop!" I said, "Say stop when your balloon falls." It was not perfect but I felt my team listened and we completed the challenge. When we help each other work together we are able to do the challenge. (PJ)

This particular student believed they were able to help other classmates within the Balloon Trolley activity, through communicating a strategy they believed would help their group. Balloon Trolley was one of the most difficult activities for the students to demonstrate successful completion; however, the experience itself created opportunity for students to practice IIRS. A different student spoke about her ability to help others through a teachable moment:

I saw someone struggling with [catching in group juggle]. This was important for me to help because I felt I had a moment to teach someone something. I asked, "Do you need help?" He said, "Fine by me." So I taught him a way to catch it better. It took awhile but he got it. (SI, AU, G3)

The decision to teach was seen by this student as using the helping others IIRS. Helping others and responsibility were the two most written and spoken about of the four IIRS.

4.3.3. Developing Leadership. Illustrated in Figure 5, one student pointed out how important it was to use leadership while engaged in the ABL activities, "I do think we have been working on the [IIRS]. In the dead ant game I feel we worked as a team and used leadership by helping people. We encouraged, not to boss people around but to help them" (SI, 4, G3). One student indicated how important listening was, as an example of leadership, "Some people were being good leaders in the toss game by listening to others suggestions"

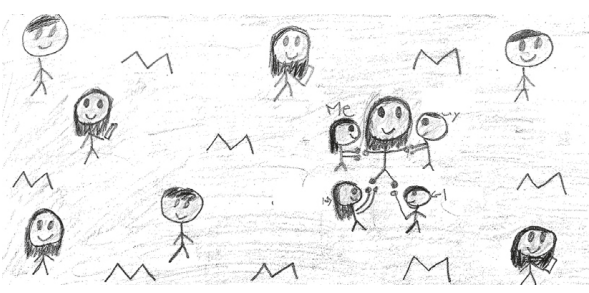

FIgURE 6: Photo journal drawing representing stage 3: developing responsibility.

(SI, 4, G5). While another student indicated the same activity (i.e., toss five) brought about the use of leadership:

In [toss five] we learned how to be patient even if someone dropped the bean bag and we had to start all over again. You can always say, "Good try" if someone drops the bean bag. This is being nice when you stay positive instead of being mean. When you show everyone patience in a nice way this is leadership. (SI, AU, G1)

As highlighted in the previous datum, speaking out during the activities was a common practice discovered in the data corpus, "I was a leader when I told my group which character to perform in the [giants, wizards, and elves activity]" (SI, 5, G5). One student recalled a time where she showed leadership through helping the teacher, "I was not asked by [the teacher] to do anything but I thought it was the right thing to do, so I picked up all the cones after class. Leadership is helping others even when you don't have to" (PJ).

In this particular photo journal entry, there is a connection between voluntarily assisting the teacher and demonstrating the IIRS of leadership. The student is equating her behavior to that of leadership. In this example, there is a discernable distinction that the autonomy surrounding her assistance is associated with that of leadership.

4.3.4. Developing Responsibility. Figure 6 is a drawing of the Dead Ant Tag activity, where one student felt they were able to practice/demonstrate responsibility through helping other classmates and by following the rules:

When we were playing dead ant tag I showed responsibility by helping others who were on the ground [tagged/frozen]. I also showed responsibility when I was tagged by staying on the ground until someone took me to the hospital [hula hoop]. It is important to behave this way because being responsible helps you finish the work you need to do. (PJ)

In Figure 6, there are several students helping another student complete the task required in the activity of Dead Ant Tag. This student's photo journal is an example of how the students believed helping others, following rules, and listening to directions were acts of responsibility. The presence of responsibility was displayed as acts of "pleasing" behavior toward both teachers (i.e., the students wanted opportunity to be responsible). Several students wrote and spoke about their ability to practice responsibility through 
helping classmates in the game Dead Ant Tag, linking responsibility to helping was a common theme discovered in the data. Developing responsibility was also represented as performing act of kindness toward other classmates:

Student: During PE someone needed help on an activity. Then I helped her and she said, "Thank you very much." It was important to me to help because I want to show people that I am responsible.

Researcher: Why do you want to show others you are responsible?

Student: This way they think I am kind and this way I can develop trust with them so they will trust me to do other things with them. (II, 5)

This student believed that her responsible behavior would lead to other desirable outcomes, such as the perception that they are a kind and trusting person.

The students acknowledged that opportunities existed within the ABL unit to develop the four IIRS. The students recognized that using these IIRS presented beneficial outcomes for them and their fellow classmates. The findings that emerged from this theme represented students' consciously identifying personal development (i.e., stage 3 ) with the IIRS that were introduced, practiced, and assessed in the ABL unit.

4.4. Benefit of IIRS Outside of PE. The transferring stage of the ABL outcome model emerged as the students' ability to recognize the use and/or benefit of the IIRS outside of the structured PE lesson. Transferring of the four IIRS was discovered across all data sources. Transferring SEL skills is paramount, if not one of the most important goals for any adventure educator. However, transferring the taught content from classroom to the "real-world" can be a difficult task to accomplish for any teacher and/or student. All four IIRS were represented within the data corpus at stage 4-transferring. Thus, the elementary school students in this study were able to recognize the use and or/benefit of commitment, helpful presence, leadership, and responsibility outside the scope of the PE lesson. Most of the IIRS examples of transfer provided by the students involved playing sports and instances that occurred at home.

4.4.1. Transferring Commitment. One student wrote about a time they gave up during a swim contest; however, learning about commitment provided insight into the value of being able to finish any task for which they start:

Commitment is to believe in yourself, follow your heart, and never give up. For instance, I was swimming in a race. I gave up because I thought it doesn't matter, I don't need to win. But I now know that if I start something I should never give up. (WJ)

The students wrote and spoke about the importance of never giving up, perseverance in the face of challenge. One student's journal entry illustrated the concept of perseverance using a sport example to represent commitment:

Commitment is not giving up on the things you love. I was playing soccer. My team was losing. My legs and feet were sore, I wanted to give up, but didn't want to let my team down. I was able to stay in the game and believe that my team still could play well. (WJ)

Commitment as an IIRS was also represented with examples from home. One student spoke about the importance of keeping another relative safe, as a means of commitment:

When my cousin was playing around the pool and she is only 3. If they fall into the spa that wouldn't be good, so my friend and I went over to them and helped them to stay far away from the pool. We were committed to being safe. (SI, $A U, G 2)$

Another example of a student identifying with the use of commitment from home was linked with the ideal of honesty:

When I am at home I am committed to tell the truth by telling my parents if I make a mistake. If I broke a vase I should be honest and tell them because if I lie then that's not commitment to being a truthful person. (SI, 4, G3)

Students in this study were able to demonstrate an understanding of how they were or could use the IIRS of commitment outside the school environment.

\subsubsection{Transferring a Helpful Presence (Helping} Others). One student spoke about his ability to help a classmate who had injured his knee:

Student: A few days ago I helped my friend Steve get up at lunch. I got Steve a band aide and he said thank you. It's important to always help others in need because sometimes things can really go bad and I try to help them as much as I can. (SI, AU, 4)

Another student wrote about helping his teacher, "I helped my teacher with the desks [organize and straighten desks in the classroom]. I think it's important to help my teacher when I can. It is good to help others and a way to be nice" (SI, AU, 2). One student represented the transfer stage through her photo journal, indicating that she was able to help someone outside of PE:

My brother needed help with his packet that Mr. Z gave him. My Mom asked if I could help him. I said "sure." Instead of like, "oh he had the whole week to do it and he could of done it by himself." But instead of being mean and letting him fail I helped him. (PJ)

Being helpful to others was the most prevalent of the four IIRS. The students in this study used this IIRS the most in presenting examples of how they were able to use it outside of PE. 
4.4.3. Transferring Leadership. The construct of leadership was linked closely with the act of helping others. Under this, IIRS are examples from students of how they have exhibited leadership through kindness toward others. One student spoke about helping a neighbor as one way they have demonstrated leadership, "I have a neighbor who had a project due. She needed help and couldn't do it all by herself so she asked me if I could draw the pictures. I showed leadership by helping her with her pictures" (SI, AU, G3). Another student believed that they fulfilled the responsibilities of a leader by helping teammates on a sports team, "I play sports and I show leadership by helping my teammates understand it so that they can be better at softball and help the entire team" (SI, AU, G3). While one student indicated a very small act of kindness toward them demonstrated leadership, "Tommy (pseudonym) helped me with opening my backpack the other day. That was leadership because he helped" (SI, AU, G4). The IIRS of leadership was the most difficult for the students to define, express, and represent the least amount of coded datum for stage 4 -transferring.

4.4.4. Transferring Responsibility. As with the three previous IIRS, transfer of responsibility was illustrated primarily through examples of playing sports and occurrences from home. One student wrote about an instance at a cheer competition that provided opportunity for her to demonstrate responsibility:

One day my Mom drove me to a cheerleading competition. My group was upset because the judge told us we were in 4th place. When I saw how upset my group was I told them, "We will do better next time." My group was upset but I showed responsibility by keeping a positive attitude and trying to pick my group up by saying this to them. (WJ)

As this narrative from this student illustrates, most students were able to provide clear examples of how they were able to be responsible outside the context of the school environment. Some of the examples for stage 4-transfer were quite personal. One student spoke about his father's disability, "At home I am responsible because my Dad is disabled and my Mom is not home most of the time she is working. So I am doing things to take care of my Dad" (II, 4). Responsibility was also represented through "helping" out others:

Well, I was responsible and helped my best friend. She got mad at her Mom. She had a little tantrum. I tried to cheer her up and make her feel good. She was having trouble with her homework and was upset and mad and stressed. She gets a lot of homework, a lot. So I wanted to help her, to cheer her up. (SI, 5, G4)

This previous piece of datum shows that this particular student believed she was acting in a responsible fashion by helping her best friend. The final example highlights a students desire to replace a broken glass that they felt responsible for upon it breaking:
This morning when I was trying to clean at my house. I was cleaning and I dropped a glass cup. It broke. I was really mad about myself. I was really sorry. So for Christmas I am going to use my responsibility and buy something to replace it. (SI, 5, G3)

For this subtheme, there is plausible illustration that the students understood and could provide examples of how they were able to transfer the IIRS of responsibility outside of PE.

The findings from the data corpus represent an established ability for this group of students to recognize the use and/or benefit of the IIRS outside of PE. The students' lived experience with the ABL unit and the examples they provided with the IIRS emerged as representation of transfer (i.e., illustrating stage 4 credibility at the elementary level).

4.5. Summary of Findings. The data that were discovered from this study signified that the elementary students were able to connect, value, develop, and transfer the four IIRS that they had been provided opportunity to actively engage in over the course of the ABL unit. The findings provide plausible evidence that IIRS outcomes from the implementation of an ABL unit of instruction are possible to achieve at the elementary school level. In regard to stage 1 (i.e., connecting), the students showed an affinity toward the $\mathrm{ABL}$ activities. The students demonstrated enjoyment, had opportunity to be physically active, and understood that there was a purpose behind doing ABL. At stage 2 (i.e., valuing), the students could articulate the meaning of commitment, helping others, leadership, and responsibility and provided evidence that they justified the importance of learning about these IIRS. Stage 3 (i.e., developing) data represented student identifying personal development with the four IIRS that were covered in the ABL unit. Finally, the data from stage 4 (i.e., transferring) emerged as students being able to recognize the use and/or benefit of the IIRS. In stage 4 , students were able to apply the use of the IIRS by providing examples of their use in specific sport and home occurrences.

\section{Discussion}

This section will cover the impact the ABL unit had on the student, the positive impact and challenges the teachers experienced with the unit, and the implications of the study. First, the lived experience of the participants is discussed, as it related to the positive emotionality that $\mathrm{ABL}$ created for the students. Next, the implementation of the ABL unit by the teachers is discussed, including some of the challenges with using the SADDM, and a potential way to help promote a more student-centered debrief. Finally, the discussion section ends with implications for elementary teachers and future research directions that should be considered.

5.1. Student Lived Experience with $A B L$. When planned and implemented correctly PE can be an impactful subject for children [3]. Novel and enticing curriculum, like ABL, can 
help students enjoy being physically active, while at the same time learn about various IIRS [9]. The lived experience of the students illustrated four themes that produced strong, positive emotionality: affinity toward $A B L$, meaning and importance of the IIRS, identifying personal development with the IIRS, and benefit of IIRS outside of PE. The phenomenon of positive emotionality relates to one's perception of an emotion that leads to personal growth [46]. For example, the students in this study interpreted their emotionality in $\mathrm{ABL}$ as fun and rewarding, an experience that contributed or added to their personal growth (e.g., being able to be physically active and connect with, develop, and transfer the four IIRS). The students connected with ABL and the IIRS and recognized the experience as a social, emotional, and physical amalgam, as an opportunity to have fun, be social with friends, and learn various IIRS. Social and emotional supportive classrooms have been shown to enhance student conduct, engagement, and enjoyment $[47,48]$. When teachers can develop classroom settings full of positive emotionality, where safety, security, and caring is paramount, then, in essence, they stand a greater chance of reaching academic goals with students [49].

All the participants in this study acknowledged that they thoroughly enjoyed $\mathrm{ABL}$, unlike previous $\mathrm{ABL}$ studies where some students were reluctant and unwilling to participate $[10,18]$. As seen in previous works, using adventure-type curriculum can promote the level of enjoyment for students in PE compared to a "traditional" class [44, 45]. Previous investigations have shown social benefit (i.e., IIRS) from students participating in adventure-type activities within the school environment (i.e., place-based approach); however, these studies have been at the secondary, not elementary school level $[10,50]$. There have also been previous studies that have used adventure-type activities to develop and transfer IIRS; however, most of these studies involve offcampus adventure sites, often referred to as challenge courses, and do not address place-based adventure programs [51-53]. This study adds to the ABL literature, specifically from an elementary school context in regard to providing $\mathrm{PE}$ students with an enticing curriculum, where meaning, importance, development, and benefit of the IIRS were nurtured.

5.2. ABL Facilitation: The Good, the Bad, and the Follow the Road Strategy. Although the teachers were not formal participants in regard to the aim of the study (i.e., not part of the research questions, data collection, or analysis), there were a few take-aways worth discussing regarding their facilitation of the ABL unit. Through informal discussion and observation with the teachers, the researchers noted items that were considered good and bad as it pertained to the delivery of unit.

5.2.1. The Good. The teachers in this study found the ABL unit to be novel and beneficial for students. The PE specialist became enamored over ABL, and admittedly, was surprised how much the students enjoyed the curriculum. The teachers commented on what a profound experience using ABL was to help students with SEL and specifically the selected IIRS.
Both teachers acknowledged that there was a learning curve with teaching $\mathrm{ABL}$ for the first time however, were very pleased with the outcomes of the unit and spoke highly of using ABL for future classes. The teachers found that there were relatively low concerns with teaching of the experiential $\mathrm{ABL}$ activities. The PE specialist facilitating the activities portion of the unit found the training and written instructions to be adequate in providing enough information needed to deliver them appropriately to the students. The PE specialist mentioned that some of activities flowed better than others, but in the end she was quite pleased with how the activity portion of the unit unfolded.

5.2.2. The Bad. As found in previous studies [10, 18, 21, 54], the use of the SADDM within ABL can be a credible way to lead a reflection session with the K-12 students. However, challenges can exist and are experienced by teachers who have implemented $\mathrm{ABL}$ and the SADDM in the K-12 settings $[18,34]$. The teachers in this study found ABL to be a fun and a valid curricular model, though there were some challenges along the way. Using the SADDM presented challenges, with both teachers having a hard time consistently using the reflective strategies embedded within the model for each lesson. Both teachers thought they would be able to lead a group reflective session using the SADDM with no problems; however, they found the open-ended, semiguided nature of the $\mathrm{ABL}$ debrief was quite challenging. Both teachers did allot time for students to openly discuss the lesson topic; however, they found it difficult to allow students some freedom in steering the direction of the conversation and empowering students to take more ownership of the discussion. Additionally, the teachers had a difficult time implementing the Who Sits Where, Start the Car, and Follow the Road SADDM strategies. With the regard to Who Sits Where and the Start the Car strategies, the teachers commented that they sometimes forgot and did not realize how important the circular group formation (i.e., Who Sits Where) and use of an engaging method to start the conversation (i.e., Start the Car) could be for the debrief conversations. For the Follow the Road strategy, both teachers mentioned that this strategy was the most difficult to use, and more training with this strategy would have proven to be useful.

5.2.3. The Follow the Road Strategy. Based upon the PI's observations and the challenges encountered and expressed by each of the teachers, specific instructions (Table 2) were created for the Follow the Road strategy (i.e., Driving Instructions for Following the Road). These instructions can be thought of as a supplement to the existing SADDM. The aim of these instructions is to help simplify this part of the reflective process for teachers who consider themselves novice in using the SADDM with the debrief portion of ABL.

This Following the Road strategy should be considered as a recommended teaching tool. The additional techniques for the Follow the Road portion of the debrief (i.e., note taking, paraphrasing, probing questions, acknowledging, and contributing) may prove useful for novice ABL facilitators than using the existing SADDM alone. 
TABLe 2: Driving instructions for Following the Road (Supplement for the Sunday Afternoon Drive Debrief Model).

Driving instructions for Following the Road

What is the Follow the Road strategy within the Sunday Afternoon Drive Debrief?

The Follow the Road strategy is the metaphor used to describe how the facilitator can choose a powerful and potentially impactful conversation thread or discussion topic, based upon initial student responses.

Why is the Follow the Road strategy important for ABL facilitators to use during the debrief?

The Follow the Road strategy is meant to help the facilitator focus and deepen the conversation. Focus the discussion by making the message, point, or idea clear and recognizable. Deepen the discussion by making the message, point, or idea centralized and relevant for students. Thus, allowing the students to connect with what is being spoken about and construct personal meaning from the centralized message, point, or idea.

Here are five techniques* an ABL facilitators can use to increase the likelihood of making the debrief a powerful and memorable discussion for students:

(i) Note taking - the facilitator should take small, manageable notes on key words or phrases they hear in the debrief conversation based upon student responses. These notes can then be used to help the facilitator focus the conversation toward the next SADDM strategy of generalizing a central message, point, or idea (i.e., nearing the Final Destination).

(ii) Paraphrasing - if a student makes a powerful statement the facilitator should try to briefly paraphrase the remark. This proves helpful for two reasons. First, it helps to clarify the student's response and allows the facilitator to check for understanding. Secondly, it allows other students in the class to hear the response one more time.

(iii) Probing questions - to help deepen the conversation, a facilitator can ask probing questions such as, "Can you explain what you said further" or "Why do think that to be true" or "Can you rephrase what you just said." Probing questions allow opportunity for the student to provide additional clarification on his or her own thoughts.

(iv) Acknowledging - students may be hesitant to speak during the debrief. Teachers praise and acknowledgement (when congruent) can be a way to encourage students to speak and recognize those students who are making contributions to the discussion.

(v) Contributing - teachers should find moments in the discussion to contribute by adding their own thoughts and insight. However, teacher comments should be timely and balanced with student comments (i.e., the intent is still a student-centered reflection).

*These five techniques do not have to be used in any particular order or amount.

5.3. Implications and Future Research Directions. This section covers implications for the K-12 teachers and potential directions for future research based upon the findings from this study. The outcome model for ABL was found to be a credible framework for determining what the students took from participating in the $\mathrm{ABL}$ unit. The researchers recommend teachers consider designing their ABL unit with specific activities and IIRS in mind (i.e., choosing 3-4 IIRS that the teacher would like the students to potentially value, develop, and transfer). Recommendations also include having the K-12 teachers use the newly designed SADDM Driving Instructions for Following the Road to gain deeper comprehension of the pedagogical tools that can be used for a successful debrief (Table 2).

In regard to future research, there should be more inquiry on which preinstruction training methods work best for teachers to acquire a deeper understanding of the debrief process. Further research is needed to determine how best to support/train elementary teachers on how to properly conduct an ABL unit. Proper training is a key component for teachers who currently may be reluctant to implement ABL. The researchers are still unclear on what preinstruction training methods work best in helping teachers gain an enduring understanding of the debrief process. Studies that specifically look at debrief training might include the use of preinstruction debrief workshops, video examples, and expert(s) leading debrief sessions as part of the investigation.

One potential avenue for future research could be to explore the use of the stimulated recall (SR) method [55-57]. SR can be used as a method to allow participants to recall their thinking during an event when prompted by a videotape. Research on using SR within $\mathrm{ABL}$ is needed. This type of method may prove useful in capturing teacher behavior during the first few debrief sessions, for use as part of debrief training, and to capture research data on the fidelity of implementing the SADDM.

\section{Concluding Remarks}

In summary, the findings from this study add to the current literature by suggesting that the ABL delivered at this elementary school was helpful in producing perceived SEL for the 5th grade students. In addition, the ABL Student Outcome Model was found to be a credible framework in theorizing what the students would be able to acquire upon completion of the unit. Although perceived as an extremely promising pedagogical tool to use by the teachers, the Following the Road strategy within the existing Sunday Afternoon Drive Debrief Model was difficult to fully implement. However, based upon consultation with the teachers, the Driving Instructions for Following the Road (i.e., five techniques that ABL facilitators can use to increase the likelihood of making the debrief a powerful and memorable discussion for students) approach for guiding this part of the debrief was conceptualized. Further inquiry testing this newly reconceptualized debrief approach is suggested for future ABL studies.

ABL has the potential to influence the SEL of elementary school children and may even promote a more desired learning environment for students. The findings from this study support the assertion that supportive and positive human relationships are the cornerstone to a well-rounded education for the "whole 
child." It behooves all school stakeholders (e.g., parents, teacher, administrators, and students) to set aside some allotted time for the purposeful use of a SEL curriculum (like ABL) to help students recognize the value in developing and transferring IIRS. This study also highlights the role PE can play in promoting SEL and IIRS. PE is more than physical activity, more than fun and games, more than keeping students busy, happy and good. Elementary PE can create space to help students gain a deeper understanding and appreciation for selected IIRS, in an effort to help them value, develop, and transfer these important life skills. Within PE, ABL creates opportunity for students to experientially apply IIRS within an assortment of intrinsically motivating and enjoyable cooperative activities.

\section{Conflicts of Interest}

The authors declare that there are no conflicts of interest regarding the publication of this paper.

\section{References}

[1] A. Casey, "Models-based practice: great white hope or white elephant?," Physical Education and Sport Pedagogy, vol. 19, no. 1, pp. 18-34, 2014.

[2] Society of Health and Physical Educators, National Standards and Grade-Level Outcomes for K-12 Physical Education, Champaign, IL, USA, Human Kinetics, 2014.

[3] D. Siedentop, P. A. Hastie, and H. van der Mars, Complete Guide to Sport Education, Human Kinetics, Champaign, IL, USA, 2nd edition, 2011.

[4] B. Dyson and A. Casey, Cooperative Learning in Physical Education: A Research Based Approach, Routledge, New York, NY, USA, 2014.

[5] A. G. Launder, Play Practice: Engaging and Developing Skilled Players from Beginner to Elite, Human Kinetics, Champaign, IL, USA, 2nd edition, 2013.

[6] G. Graham, S. A. Holt-Hale, and M. Parker, Children Moving: A Reflective Approach to Teaching Physical Education, McGraw-Hill, New York, NY, USA, 9th edition, 2012.

[7] L. L. Griffin and J. I. Butler, Teaching Games for Understanding: Theory, Research, and Practice, Human Kinetics, Champaign, IL, USA, 2004.

[8] C. B. Corbin and R. Lindsey, Fitness for Life, Human Kinetics, Champaign, IL, USA, 5th edition, 2006.

[9] B. Dyson and S. Sutherland, "Adventure education in your physical education program," in Standards-Based Physical Education Curriculum Development, J. Lund and D. Tannehill, Eds., pp. 229-254, Jones and Bartlett Learning, Burlington, MA, USA, 5th edition, 2014.

[10] P. T. Stuhr, S. Sutherland, J. Ressler, and E. M. Ortiz-Stuhr, "Students perception of relationship skills during an adventure-based learning unit within physical education," Australian Journal of Outdoor Education, vol. 18, no. 1, pp. 27-38, 2015.

[11] Y. S. M. Tan and M. Atienco, "Unpacking a place-based approach-What lies beyond? Insights drawn from teachers' perceptions of outdoor education," Teaching and Teacher Education, vol. 56, pp. 25-34, 2016.

[12] S. Sutherland and M. F. Legge, "The possibilities of "doing" outdoor and/or adventure education in physical education/teacher education," Journal of Teaching in Physical Education, vol. 35, no. 4, pp. 299-312, 2016.
[13] M. Cosgriff, "Walking our talk: adventure based learning and physical education," Journal of Physical Education New Zealand, vol. 33, no. 2, pp. 89-98, 2000.

[14] M. Brown, "Adventure education and physical education," in The Handbook of Physical Education, D. Kirk, D. Macdonald, and M. O'Sullivan, Eds., pp. 685-702, SAGE Publications, Thousand Oaks, CA, USA, 2006.

[15] P. T. Stuhr, S. Sutherland, J. Ressler, and E. M. Ortiz-Stuhr, "The ABC's of adventure-based learning," Strategies: A Journal for Physical and Sport Educators, vol. 29, no. 1, pp. 3-9, 2016.

[16] B. Dyson, "Student voices in two alternative elementary physical education programs," Journal of Teaching in Physical Education, vol. 14, no. 4, pp. 394-407, 1995.

[17] J. Gehris, J. Kress, and R. Swalm, “Students' views on physical development and physical self-concept in adventure-physical education," Journal of Teaching in Physical Education, vol. 29, no. 2, pp. 146-166, 2010.

[18] S. Sutherland and P. T. Stuhr, "Reactions to implementing adventure-based learning in physical education," Sport, Education and Society, vol. 19, no. 4, pp. 489-506, 2014.

[19] S. Sutherland, P. T. Stuhr, and S. Ayvazo, "Learning to teach: pedagogical content knowledge in adventure-based learning," Physical Education and Sport Pedagogy, vol. 21, no. 3, pp. 233248, 2016.

[20] D. A. Kolb, Experiential Learning, Prentice-Hall, Englewood Cliffs, NJ, USA, 1984.

[21] P. T. Stuhr and S. Sutherland, "Undergraduate perceptions regarding the debrief process in adventure-based learning: exploring the credibility of the Sunday afternoon drive debrief model," Journal of Outdoor Recreation, Education, and Leadership, vol. 5, no. 1, pp. 18-36, 2013.

[22] S. Sutherland, P. T. Stuhr, and J. Ressler, "The Sunday afternoon drive debrief model," Journal of the International Society for Comparative Physical Education and Sport, vol. 34, no. 2, pp. 5-12, 2012.

[23] J. Dewey, Experience and Education, Simon \& Schuster, New York, NY, USA, 1997.

[24] S. Priest and M. Gass, Effective Leadership in Adventure Programming, Human Kinetics, Champaign, IL, USA, 2005.

[25] L. Joplin, "On defining experiential education," Journal of Experiential Education, vol. 4, pp. 17-20, 1981.

[26] J. W. Pfeiffer and J. E. Jones, The 1980 Annual Handbook for Group Facilitators, University Associates, San Diego, CA, USA, 1980.

[27] V. Walsh and G. Golins, The Exploration of the Outward Bound Process Model, Outward Bound School, Denver, CO, USA, 1976.

[28] R. Miettinen, "The concept of experiential learning and John Dewey's theory of reflective thought and action," International Journal of Lifelong Education, vol. 19, no. 1, pp. 54-72, 2000.

[29] J. Schenck and J. Cruickshank, "Evolving Kolb: experiential education in the age of neuroscience," Journal of Experiential Education, vol. 38, no. 1, pp. 73-95, 2015.

[30] D. A. Kolb and A. Y. Kolb, "Learning styles and learning spaces: enhancing experiential learning in higher education," Academy of Management Learning \& Education, vol. 4, no. 2, pp. 193-212, 2005.

[31] J. Seaman and A. Rheingold, "Circle talks as situated experiential learning: context, identity, and knowledgeability in learning from reflection," Journal of Experiential Education, vol. 36, no. 2, pp. 155-174, 2013.

[32] S. Priest and M. Naismith, "A model for debriefing experiences," Journal of Adventure and Outdoor Leadership, vol. 10, no. 3, pp. 20-22, 1993. 
[33] S. B. Bacon, The Evolution of the Outward Bound Process, Outward Bound USA, Greenwich, CT, USA, 1987.

[34] S. Sutherland, P. T. Stuhr, and J. Ressler, "Adventure-based learning and reflection: the journey of one cohort of teacher candidates," International Journal of Human Movement Science, vol. 5, no. 2, pp. 5-24, 2011.

[35] S. B. Merriam and E. J. Tisdell, Qualitative Research: A Guide to Design and Implementation, Jossey-Bass, San Francisco, CA, USA, 4th edition, 2016.

[36] R. E. Stake, The Art of Case Study Research, SAGE Publications, Thousand Oaks, CA, USA, 1995.

[37] L. Frank, Journey Toward the Caring Classroom: Using Adventure to Create Community, Oklahoma City, OK, USA, Wood 'N' Barnes Publishing, 2nd edition, 2013.

[38] J. Panicucci and N. Stratton, Adventure Curriculum for Physical Education: Elementary School, Project Adventure, Beverly, MA, USA, 2003.

[39] California Department of Education, $P E$ Framework for California Schools, 2017, https://www.cde.ca.gov/ci/pe/cf/ documents/peframework2009.pdf.

[40] S. M. Treadwell and N. Taylor, "PE in pictures: using photovoice to promote middle school students' reflections on physical activity during free time," Journal of Physical Education, Recreation \& Dance, vol. 88, no. 4, pp. 26-33, 2017.

[41] E. G. Guba and Y. S. Lincoln, Fourth Generation Evaluation, SAGE, Newbury Park, CA, USA, 1989.

[42] J. Corbin and A. Strauss, Basics of Qualitative Research: Techniques and Procedures for Developing Grounded Theory, SAGE, Thousand Oaks, CA, USA, 4th edition, 2014.

[43] C. Perry and O. Jensen, "Approaches to combining induction and deduction in one research study," Australian and New Zealand Marketing Academy Conference, Massey University, Auckland, New Zealand, October 2001.

[44] A. Doering and G. Veletsianos, "What lies beyond effectiveness and efficiency?" adventure learning design," Internet and Higher Education, vol. 11, no. 3-4, pp. 137-144, 2008.

[45] J. Fernández-Río and C. Suarez, "Feasibility and students' preliminary views on parkour in a group of primary school children," Physical Education and Sport Pedagogy, vol. 21, no. 3, pp. 281-294, 2016.

[46] P. T. Stuhr, S. Sutherland, and P. Ward, "Lived-positive emotionality in elementary physical education," Pedagogies: An International Journal, vol. 7, no. 2, pp. 165-181, 2012.

[47] M. A. Brackett, M. R. Reyes, S. E. Rivers, N. A. Elbertson, and P. Salovey, "Classroom emotional climate, teacher affiliation, and student conduct," Journal of Classroom Interaction, vol. 46, no. 1, pp. 27-36, 2011.

[48] M. Woolley, K. Kol, and G. Bowen, "The social context of school success for Latino middle school students: direct and indirect influences of teachers, family, and friends," Journal of Early Adolescence, vol. 29, no. 1, pp. 43-70, 2009.

[49] N. Noddings, The Challenge to Care in Schools: An Alternative Approach to Education, Teachers College Press, New York, NY, USA, 1992.

[50] S. L. Gibbons, V. Ebbeck, R. Y. Concepsion, and K. K. Li, “The impact of an experiential education program on the self-perceptions and perceived social regard of physical education students," Journal of Sport and Exercise Psychology, vol. 32, no. 6, pp. 786-804, 2010.

[51] D. Cason and L. Gillis, "A meta-analysis of outdoor adventure programming with adolescents," Journal of Experiential Education, vol. 17, no. 1, pp. 40-47, 1994.

[52] J. S. Glass and J. M. Benshoff, "Facilitating group cohesion among adolescents through challenge course experiences," Journal of Experiential Education, vol. 25, no. 2, pp. 268-277, 2002.
[53] J. Hattie, H. W. Marsh, J. T. Neill, and G. E. Richards, "Adventure education and outward bound: out-of-class experiences that make a lasting difference," Review of Educational Research, vol. 67, no. 1, pp. 43-87, 1997.

[54] S. Sutherland, P. T. Stuhr, and J. Ressler, "Group processing in cooperative learning: using the Sunday afternoon drive debrief model," Active + Healthy: Australian Council for Health, Physical Education and Recreation (ACHPER), vol. 21, no. 2, pp. 12-14, 2014.

[55] J. Lyle, "Stimulated recall: a report on its use in naturalistic research," British Educational Research Journal, vol. 29, no. 6, pp. 861-878, 2002.

[56] A. Mackey and S. M. Gass, Second Language Research: Methodology and Design, Lawrence Erlbaum Associates, Inc., Mahwah, NJ, USA, 2005.

[57] A. Schepens, A. Aelterman, and H. Van Keer, "Studying learning processes of student teachers with stimulated recall interviews through changes in interactive cognitions," Teacher and Teacher Education, vol. 23, no. 4, pp. 457-472, 2007. 


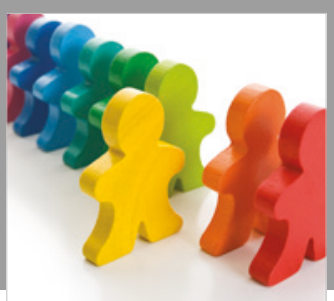

Autism

Research and Treatment
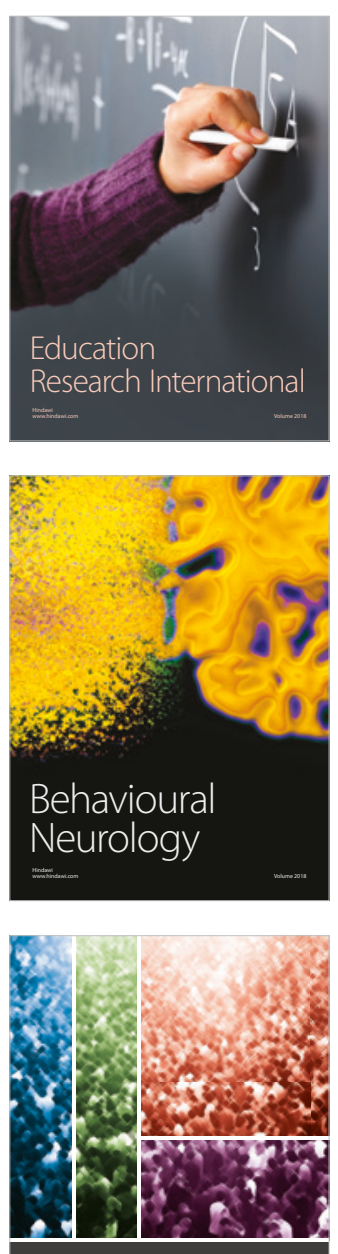

International Journal of

Population Research

$\underline{-m}$

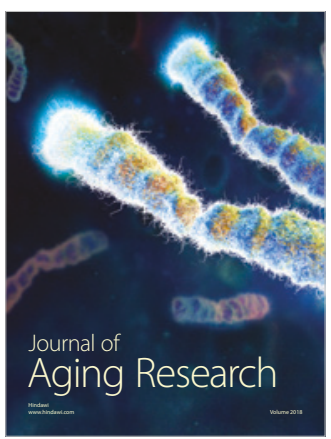

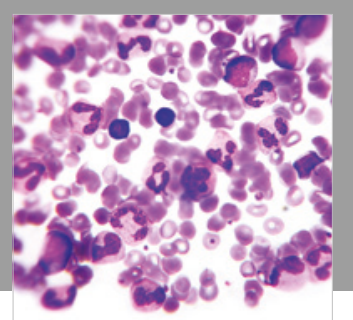

Pathology

Research International$$
=
$$

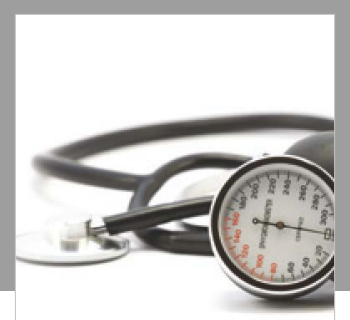

Nursing

Research and Practice

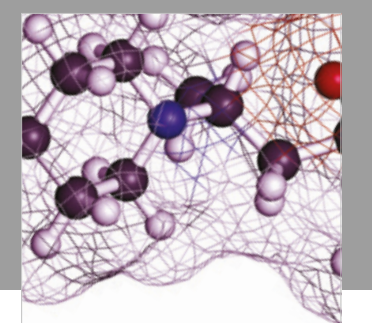

Pain

Research and Management

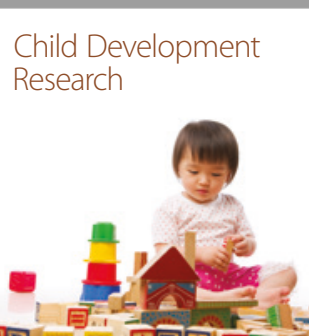

बाD

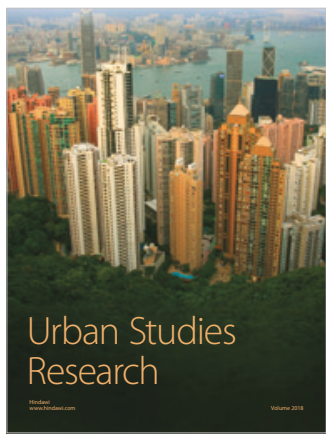

\section{Hindawi}

Submit your manuscripts at

www.hindawi.com
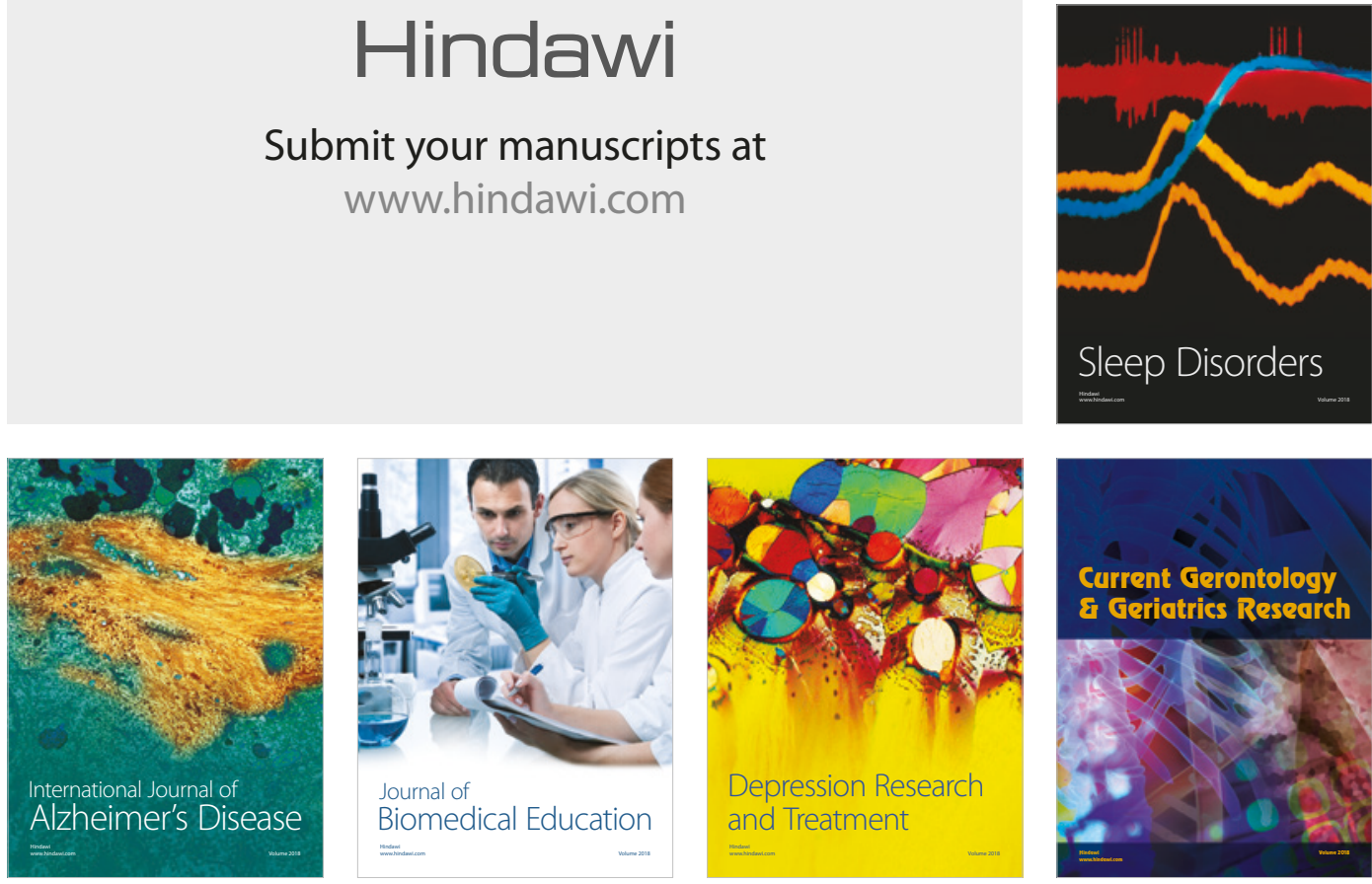

Journal of

Biomedical Education

$=$

smman

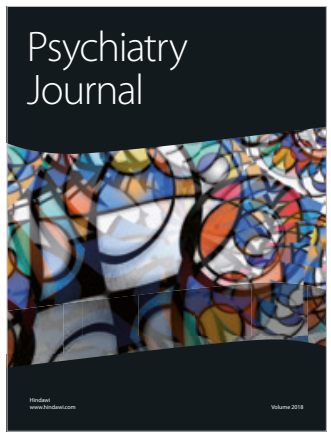

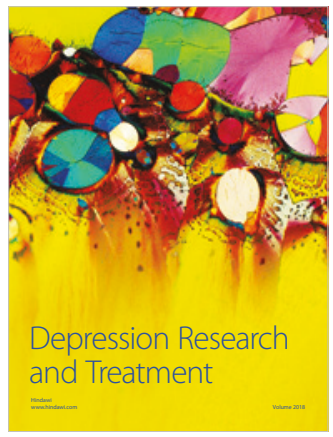
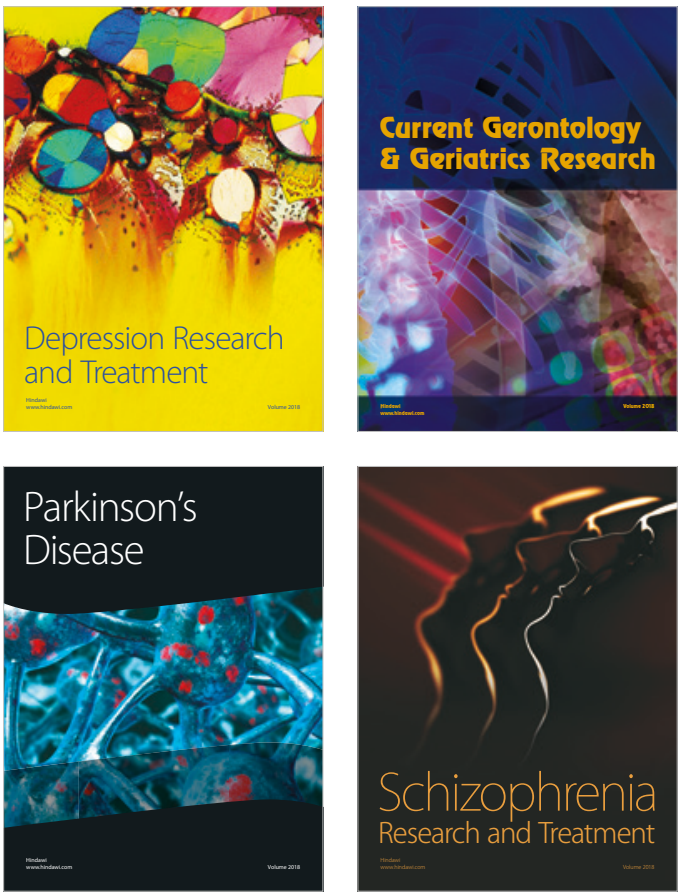